\title{
Effect of ethylene glycol dinitrate on metabolism of catecholamines and on blood pressure reaction to re-exposure
}

\author{
MASAYASU MINAMI, AKIRA OKADA, AKIHIKO TAKIZAWA, \\ and JUKO KUBOTA \\ Department of Public Health, School of Medicine, Hokkaido University, \\ Department of Public Health, Sapporo Medical College, Hokkaido, and \\ Occupational Health Service Centre, Tokyo, Japan
}

Minami, M., Okada, A., Takizawa, A., and Kubota, J. (1972). Brit. J. industr. Med., 29, 321-327. Effect of ethylene glycol dinitrate on metabolism of catecholamines and on blood pressure reaction to re-exposure. Male Donryu rats were divided into two groups. One group was given $65 \mathrm{mg} / \mathrm{kg}$ per day of ethylene glycol dinitrate (EGDN) subcutaneously for five days and the other group received the same for 10 days. On the first, second, third, fourth, and fifth days after the last injection of EGDN catecholamines were estimated in the heart, brain, and adrenals and plasma 11-hydroxycorticosteroids and haemoglobin were estimated in blood. Urine samples were collected for 24 hours every other day before, during, and after the period of EGDN injection.

After five successive doses of EGDN the concentration of catecholamines in the organs increased and urinary catecholamine excretion was a little greater than from the controls. Reinjection of EGDN caused prolonged irreversible depression of the blood pressure.

After 10 successive doses of EGDN the concentrations of catecholamines in the organs were normal, but noradrenaline excretion in the urine was increased for three days. Reinjection of EGDN on the first day caused prolonged depression of blood pressure, but by five days the response had returned to the more transient depression observed in the controls.

The probability of coronary spasm is considered to be greater in the condition found after five than in that after 10 successive injections because more noradrenaline was available in the cardiac muscle as well as adrenaline in the adrenals.

After 10 successive injections the increased noradrenaline concentration in the urine reflected the raised noradrenaline level in the blood which could alleviate the depressant action of EGDN reinjection.

The clinical significance of these findings is discussed.

Because of its moderate price and low freezing point, ethylene glycol dinitrate (EGDN) mixed with glyceryl trinitrate has been used for many years for dynamite production.

At the time when the mixture contained a high proportion $(50-60 \%)$ of EGDN there were many cases of heart attack, some of which were fatal, in our country and abroad. The heart attack due to EGDN usually occurred on a Monday morning before the worker went to work. Consequently, some authors looked upon the attack as attributable to EGDN withdrawal, because the worker had not been exposed to EGDN during his day off.

Preliminary observations of the autonomic activity 
of dynamite workers in a factory in the middle of Hokkaido Island, Japan, showed higher average noradrenaline levels in the urine of an exposed group (20 persons) than in that of a control group of unexposed factory workers and medical laboratory workers (13 persons). The cold pressor test showed less rise of blood pressure among those exposed to EGDN for less than five years than among those exposed to EGDN for a longer time or among those not exposed at all. There was no correlation between urinary noradrenaline and rise of blood pressure.

We decided to investigate the relationship thought to exist between heart attack and catecholamine metabolism, as influenced by withdrawal of EGDN, by injecting rats with EGDN subcutaneously for several days and then examining at intervals the changes in blood pressure and heart rate and in catecholamine concentrations in the heart, brain, and adrenals. Previous work (Hotta and Yamada, 1963; Häggendal, Johnsson, and Lund, 1968; Vigliani, Cavagna, Locati, and Foa, 1968) has concentrated on the period of EGDN exposure, although Yoshikawa (1964, 1965) and Clark (1970) investigated the supersensitivity to adrenaline after EGDN injection in mice and rats.

\section{Methods}

Animals

Male rats of the Donryu strain (albino) were used, body weights 180 to $200 \mathrm{~g}$.

\section{EGDN injection}

Rats were given a daily subcutaneous injection of $65 \mathrm{mg} / \mathrm{kg} \mathrm{EGDN}$ as a $10 \%$ solution in olive oil. The rats comprised two groups. One group received five successive daily doses and the other received ten. Controls received $0.65 \mathrm{ml}$ of olive oil per day for five days, and were killed according to the same schedule as the experimental group.

\section{Collection of urine}

For each collection, two rats were kept in each metabolic cage and their pooled urine was collected in an Erlenmeyer flask containing $\mathrm{HCl}$, the concentration of which became 1-2 $\mathrm{N}$ by the end of the 24 hours' collection period. Urine was collected every other day. A $25-\mathrm{ml}$ portion of the acid mixture was assayed for catecholamines.

\section{Analytical methods}

On the first, second, third, fourth, and fifth days after the last injection of EGDN the rats were decapitated and exsanguinated and the heart, brain, and adrenals were dissected out. Surface blood was removed by blotting gently with filter paper.

Catecholamines were absorbed on alumina (Anton and Sayre, 1962) and estimated fluorimetrically after elution as their trihydroxyindole derivatives (Euler, 1964). From urine the recoveries were 85 to $95 \%$; from the adrenals, 80 to $95 \%$; and from the brain and the heart, 76 to $80 \%$.
Blood was heparinized; $0.02 \mathrm{ml}$ was used for haemoglobin determination and 11-hydroxycorticosteroid in the plasma of the remainder was assayed fluorimetrically by the method of DeMoor, Steeno, Raskin, and Hendrikx (1960).

Blood pressure and heart rate after reinjection of EGDN Rats given EGDN for five or 10 successive days as described above were challenged by a further injection of EGDN on the first, third or fifth day after injections had been completed. They were lightly anaesthetized with an intraperitoneal injection of $30 \mathrm{mg} / \mathrm{kg}$ of pentobarbital sodium (Mintal, Tanabe Co. Ltd.), and the trachea was cannulated. Arterial blood pressure was recorded from the carotid artery by means of Nihonkohden's pressure transducer (MP-3A). The chest lead $\left(\mathrm{C}_{5}\right)$ of the electrocardiogram was recorded by means of subcutaneous needle electrodes and the heart rate was calculated from the R-R interval. When the blood pressure had attained a steady state its value was noted and $65 \mathrm{mg} / \mathrm{kg}$ of EGDN was given subcutaneously. The blood pressure and heart rate were then recorded every 30 seconds for 3.5 to $4 \mathrm{hr}$.

\section{Results}

Catecholamines in heart, brain, and adrenals

There was no day to day variation in the concentrations of catecholamines in the controls. Mean values are shown in Table 1.

Results on experimental rats are shown in Table 2. After five successive doses of EGDN the pooled mean concentrations of noradrenaline in the heart for the first three days after the last injection were $0.62 \pm 0.05 \mu \mathrm{g} / \mathrm{g}(\mathrm{n}=12)$, significantly higher than the pooled means of the fourth and fifth days, $0.39 \pm 0.05 \mu \mathrm{g} / \mathrm{g}(\mathrm{n}=8) ;[t=4.26 ; \mathrm{P}<0.01]$ and than the controls (Table 1; P $<0.01$ ). Cerebral noradrenaline showed parallel changes. The pooled means for the first three days were $0.45 \pm 0.05 \mu \mathrm{g} / \mathrm{g}$ $(n=12)$, significantly higher than those for the fourth and fifth days, $0.31 \pm 0.03 \mu \mathrm{g} / \mathrm{g}(\mathrm{n}=8)$ $(t=3.36 ; \mathrm{P}<0.01)$ and than the controls (Table 1; $\mathbf{P}<0.01)$.

After 10 successive doses, however, there was no elevation of cardiac or cerebral noradrenaline in the first three days after the last dose of EGDN.

The pooled mean adrenaline concentration in the adrenals for the five days after five days' EGDN

\section{TABLE 1}

Catecholamine Content of Organs of Control ANIMALS (MEANS \pm SEM)

\begin{tabular}{|c|c|c|}
\hline & & $\begin{array}{c}\mu g / g \text { of wet tissue } \\
(\mathrm{n}=10)\end{array}$ \\
\hline $\begin{array}{l}\text { Noradrenaline in heart } \\
\text { Noradrenaline in brain } \\
\text { Adrenaline of adrenals }\end{array}$ & $\begin{array}{ll}\ldots & \ldots \\
\cdots & \ldots \\
. & \cdots\end{array}$ & $\begin{array}{r}0.36 \pm 0.03 \\
0.26 \pm 0.08 \\
823.5 \pm 138.1\end{array}$ \\
\hline
\end{tabular}


TABLE 2

Catecholamine Content of Organs after Daily EGDN for 5 and 10 Days

$($ MEANS \pm SEM $)(n=4)$

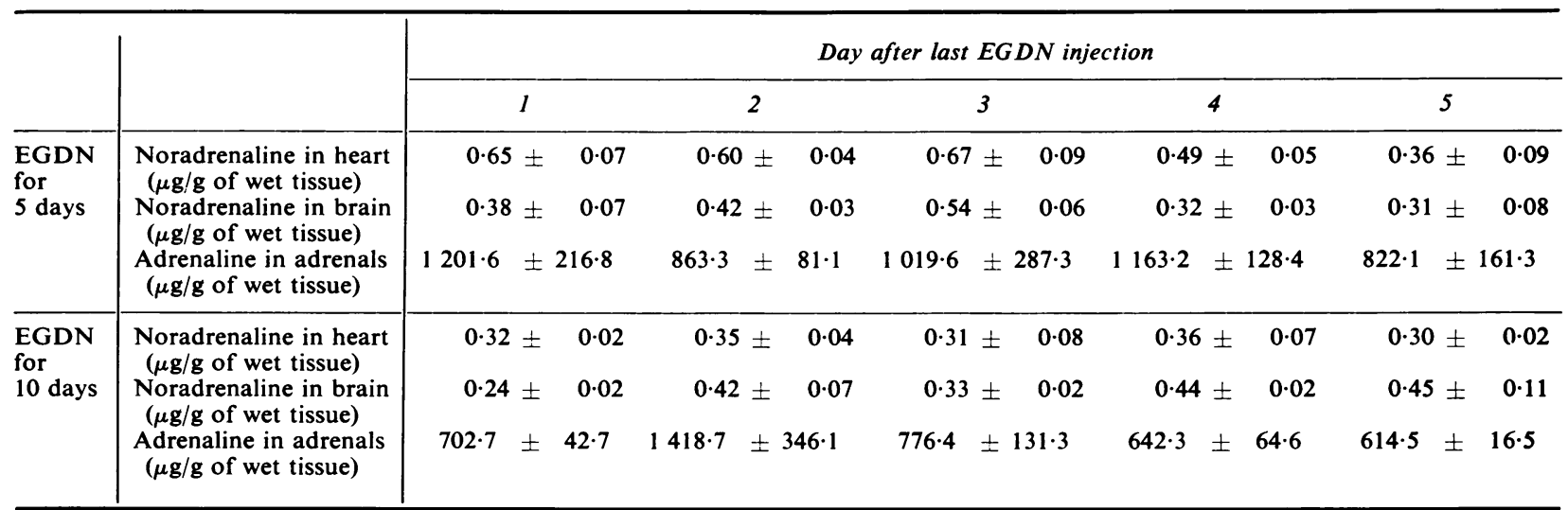

injection was $1014.0 \pm 95 \cdot 5 \mu \mathrm{g} / \mathrm{g}(\mathrm{n}=20)$, higher than the pooled mean after 10 days' EGDN injection, $749 \cdot 1 \pm 72 \cdot 4(t=2 \cdot 19 ; \mathrm{P}<0 \cdot 05)$, or than in the controls (Table 1).

\section{Urinary catecholamines}

Urinary catecholamine levels during EGDN administration did not rise above those of the controls except on the first day, and this rise was not statistically significant (Table 3).

After 10 successive injections noradrenaline output in the urine was considerably higher than in the controls on the first and third days $(P \ll 0.01)$, but after only five successive injections excretion rates were never significantly higher, although on the second day there was a slight rise (Table 3).

\section{Blood pressure and heart rate}

When a control rat was injected subcutaneously with $65 \mathrm{mg} / \mathrm{kg}$ of EGDN, the blood pressure fell to about 40 to $60 \mathrm{mmHg}$ in one minute, sometimes rebounded in a few minutes to a level as high or nearly as high as that before the injection, then fell suddenly to about 40 to $60 \mathrm{mmHg}$ again and gradually returned to normal or to about 10 to $20 \mathrm{mmHg}$ lower over 3 to 4 hours (Fig. 1). A late depression 2 to 3 hours after a single EGDN injection observed in most of the controls (and shown in Fig. 1) has also been referred to by Clark and Litchfield (1967).

Exposure to EGDN for five days or 10 days did not cause any changes in resting blood pressure and heart rate at any period up to five days after the last injection, but in half of the EGDN premedicated

TABLE 3

URINARY CATECHOLAMINES

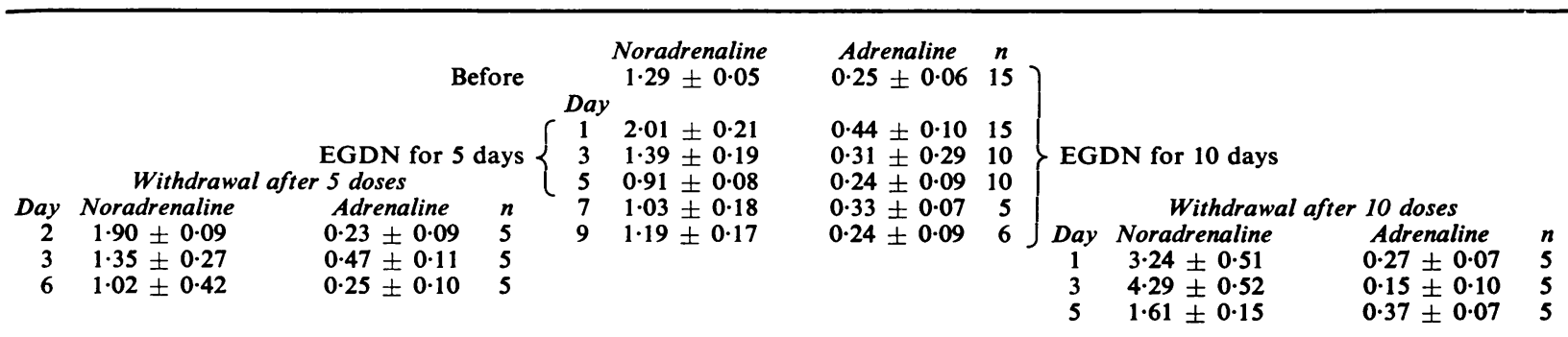

Means $\pm \operatorname{SEM}(n)$ in $\mu \mathrm{g} /$ pair of rats are shown. Urine was collected from pairs of rats for 24 hours, and the total excreted was estimated ( $n$ gives the number of pairs.) The withdrawal period was studied in half the rats after 5 successive injections, and in the remainder after 10. 


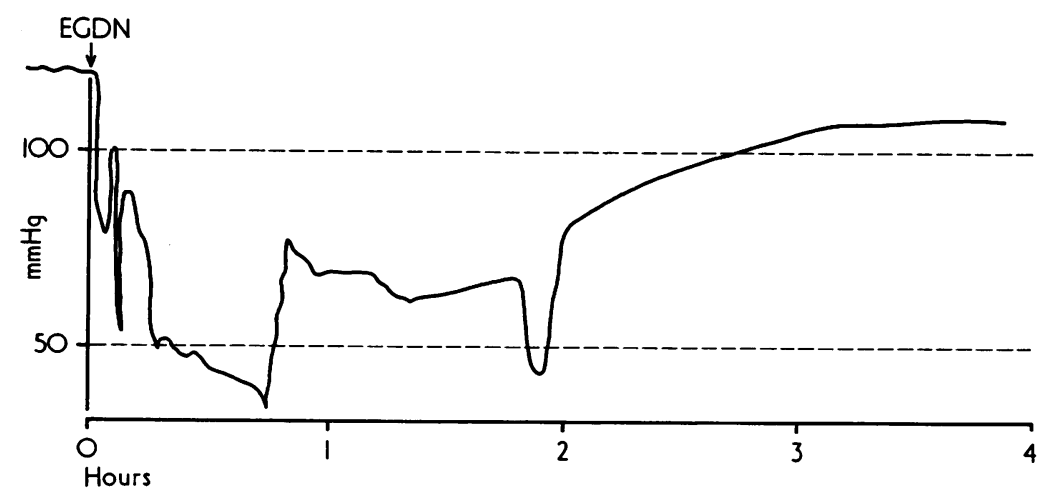

FIG. 1. Blood pressure after re-injection of EGDN: moderately depressant type.

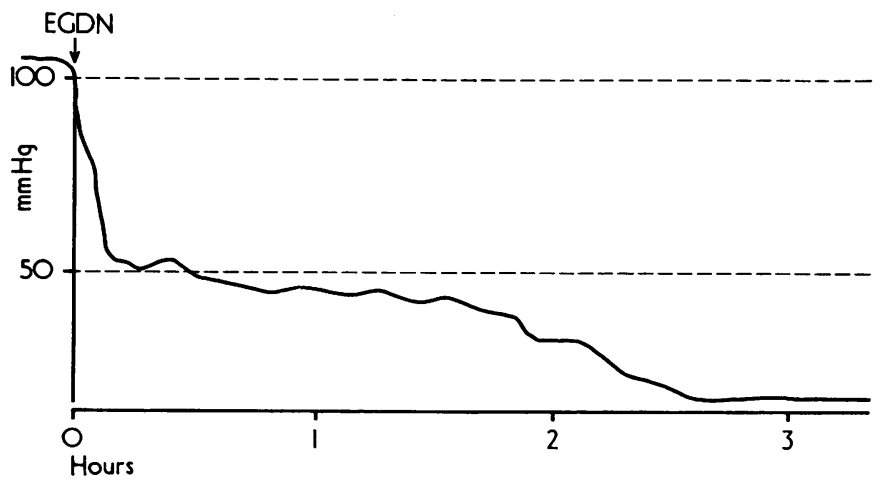

FIG. 2. Blood pressure after re-injection of EGDN: highly depressant type.

cases injection of a challenging dose produced a marked depression of the blood pressure (Fig. 2) from which it never returned to normal.

The incidence of this reaction and its variation with time after the last of the premedicating doses is shown in Table 4. In rats given 10 successive doses, marked depression was found in five out of six rats on the first day after, but on later days only in one out of six, a statistically significant change $(P<$ 0.04, Fisher's method). There was no similar statistically significant trend in rats given EGDN for five successive days. In this group, however, four of the six rats challenged three days after died 3 to 10 minutes after anaesthesia with pentobarbital sodium before EGDN reinjection. No similar cases were found in other groups.

There were no special findings concerning heart rate or arrhythmia. Blood haemoglobin values and plasma 11-hydroxycorticosteroid concentrations were normal.

\section{Discussion}

Blood haemoglobin and plasma 11-hydroxycortico-
TABLE 4

Type of Blood Pressure Response to EGDN REINJECTION AFTER WITHDRAWAL $(n=6)$

\begin{tabular}{cc|c|c}
\hline $\begin{array}{c}\text { Day after last EGDN } \\
\text { injection }\end{array}$ & $\begin{array}{c}\text { Moderate } \\
\text { depression }\end{array}$ & $\begin{array}{c}\text { Marked } \\
\text { depression }\end{array}$ \\
\hline After 5 days' injections & 1 & 2 & 1 \\
& 3 & - & 2 \\
& 4 & 4 & 3 \\
& 5 & 3 & 3 \\
\hline After 10 days' injections & 1 & 1 & 5 \\
& 3 & 3 & - \\
& 5 & 2 & 1 \\
\hline
\end{tabular}

The number of responses are shown. The two types of response are illustrated (Figs 1 and 2).

steroid levels were normal in our experiments. We determined them because most of the physiological disturbances in humans exposed to EGDN have been attributed to methaemoglobinaemia and consequent 
anaemia. Gross, Bock, and Hellrung (1942) reported severe methaemoglobinaemia in rabbits after shortterm injection of EGDN. Wilhelmi (1942), Kubota et al. (1962), and Hasegawa and Sato (1963a) also investigated this subject, the last-named attributing the electrocardiographic changes after large doses of EGDN $(200 \mathrm{mg} / \mathrm{kg}$ in the rabbit) to anaemia following methaemoglobinaemia. Many authors (Elmadjian, Hope, and Lanson, 1956; Euler and Lundberg, 1954; Euler, 1964; Funkenstein, Greenblatt, and Solomon, 1952; Goodall and Berman, 1960; Saito, 1971; and Weil-Malherbe, Smith, and Bowles, 1968) have reported that stress or detergents influence not only the metabolism of catecholamines but also the pituitary-adrenocortical system. The effects we observed after successive dosing with $65 \mathrm{mg} / \mathrm{kg}$ were not, however, on haemoglobin or on 11-hydroxycorticosteroids but on catecholamine concentrations after successive daily doses and also on the response of the blood pressure to a further challenging dose of EGDN.

To elucidate the relation between catecholamine metabolism and/or supersensitivity and EGDN poisoning would help to explain the mechanism of chronic poisoning from low EGDN exposure (Clark, 1970).

Most cases of heart attack among dynamite workers have occurred before restarting work on Monday morning, suggesting that this syndrome should be regarded as one of withdrawal from exposure to EGDN (Symanski, 1952), for by this time EGDN concentrations have fallen considerably, both in the target organs and in the bloodstream. Previous work is relevant to our approach in the present paper. Yoshikawa (1964) reported that pretreatment of mice with EGDN $(100 \mathrm{mg} / \mathrm{kg}$ in olive oil) decreased the $\mathrm{LD}_{50}$ value of adrenaline and also showed that when adrenaline $(2 \mathrm{mg} / \mathrm{kg})$ was injected daily into mice which had been treated daily with EGDN $(100 \mathrm{mg} / \mathrm{kg})$ for 14 days the death rate among the mice injected every day with adrenaline from the second day was higher than that among the mice injected every day including the first after the last injection of EGDN. Clark (1970) found that 5 hours after the last injection of EGDN $(65 \mathrm{mg} / \mathrm{kg}, 5$ days per week for 5 weeks), the heart of the anaesthetized rat was subsensitive to adrenaline-induced arrhythmias, but that 24 hours after the last injection both the heart rate and blood pressure were supersensitive to adrenaline. These findings are in line with the observation that heart attacks are most common among dynamite workers 24 to 48 hours after exposure to EGDN has terminated. Häggendal et al. (1968) reported that the mean 24-hour excretion of noradrenaline and of adrenaline in workers exposed to nitroglycerine were within the normal range. Hotta and Yamada (1963) found a decreased excretion of noradrenaline in urine collected over
8 hours among dynamite workers; on the contrary, Minami and Fukuchi (in preparation) found an increased noradrenaline output when urine was collected for 24 hours. This discrepancy does not seem to be due to the differences of urine collection time, because Vigliani et al. (1968) reported an increase of noradrenaline concentration in urine collected over 8 hours. In the same paper, Vigliani described increased catecholamine concentrations in rats' cardiac muscle after EGDN treatment for three days and tyramine-induced severe tachycardia in EGDNpremedicated rats. Hotta and Yamada (1963) and Vigliani et al. (1968) did not discuss the clinical meaning of the withdrawal syndrome.

In the following discussion one should remember that catecholamines are stored in inactive forms in storage granules and are set free by sympathetic stimulation as active forms.

The reactions to daily injection for five successive days were different from those to injection for 10 successive days. The period in which they are observed will be described as type I and type II periods respectively.

In the type I period concentrations of catecholamines in cardiac muscle, brain, and adrenals increased (Table 2) and urinary noradrenaline excretion was a little greater than in the control period (Table 3). On reinjection of EGDN, the fall in blood pressure was often persistent (Fig. 2) and markedly depressed (Table 4).

In the type II period the concentrations of catecholamines were normal but the noradrenaline excretion in urine was greater during the first three days after the last EGDN injection. The blood pressure reaction to EGDN readministration tended to recover to the type in the control group (moderate depression, Fig. 1; Table 4).

In assessing the clinical significance of the difference found in each period the observations of other authors should be taken into account. Raab, Stark, and Gigee (1959), Raab, Stark, Macmillan, and Gigee (1961), and Raab, Chaplin, and Bajusz (1964) reported that stressful situations such as restriction, exposure to cold or noise, and electric shock cause cardiac necrosis in experimental animals and this has something to do with coronary spasm and/or the direct cardiotoxic effect of noradrenaline. Accordingly, Raab et al. $(1959,1961)$ and Reichenbach, Greenhoot, and Benditt (1969) found that premedication with an MAO inhibitor, which inhibited catecholamine degradation, aggravated cardiac necrosis after stress. Schümann (1970) examined the rate of coronary flow after infusion of angiotensin at 10 to $320 \mathrm{ng} / \mathrm{min}$, and found an increased and dose-dependent output of catecholamines with a diminution of the coronary flow. The noradrenaline output induced by sympathetic stimulation decreased proportionally to the reduction in flow. 
In a rat treated with EGDN and in a type I period during which there are high concentrations of inactive catecholamines in cardiac muscle and adrenals, any stress may release the catecholamine from the stores in the organs into the bloodstream even though very little catecholamine is released from the brain into the systemic circulation (Glowinski et al., 1965). In such a situation of stress it is likely that vascular spasms, especially coronary spasm, would occur provided that little EGDN is left at its site of action (the vascular wall), for EGDN inhibits the action of catecholamines. The concentration of noradrenaline in the cardiac muscle itself was high during the first three days after the last injection of EGDN, so that by sympathetic action a more than normal amount of noradrenaline could be released from the storage site of cardiac muscle itself.

Clark (1970) attributed the initial subsensitivity of the rat heart to adrenaline to the persistence of effective concentrations of EGDN at the effector sites in the heart even though no EGDN was detectable in the blood. Later, when the EGDN had disappeared, supersensitivity was observed.

In short, the probability of coronary spasm occurrence after stress among rats treated by EGDN depends largely on the concentrations of noradrenaline and EGDN in the heart, and the sensitivity of the organ to these substances.

During the type II period, concentrations of catecholamines in the organs were normal and the depressant effect of EGDN readministration was diminishing. But noradrenaline concentration in the bloodstream, as reflected by urinary noradrenaline output (Euler, 1964), was high on the average. Coronary spasm seems less likely in this period than in the type I period, because there was less noradrenaline available in the cardiac muscle itself. The marked depression of blood pressure to the challenge of EGDN reinjection was much less frequent than in the type I period (Table 4). Probably the comparatively high noradrenaline level in the bloodstream mitigated the depressant action of EGDN like that of nitroglycerine.

In this study there was no investigation of the cardiovascular sensitivity to EGDN and/or noradrenaline. Clark (1970), after extensive experiments, reported that the supersensitivity to adrenaline after EGDN injection cannot be due to a direct action on the muscle cells of the cardiovascular system, but must involve the nervous system in some way.

Vigliani et al. (1968) suggest that EGDN changes the metabolism of catecholamines in the heart. This is in line with our findings. Our study showed that EGDN affects not only the catecholamine metabolism of the heart but also that of the brain and adrenals.

\section{References}

Anton, A. A., and Sayre, D. F. (1962). A study of the factors affecting the aluminium oxide-trihydroxyindole procedure for the analysis of catecholamines. J. Pharmacol. exp. Ther., 138, 360-375.

Clark, D. G. (1970). The supersensitivity of the rat cardiovascular system to epinephrine after repeated injections of ethylene glycol dinitrate. Toxicol. appl. Pharmacol., 17, 433-442.

_ and Litchfield, M. H. (1967). Metabolism of ethylene glycol dinitrate and its influence on the blood pressure of the rat. Brit. J. industr. Med., 24, 320-325.

DeMoor, Steeno O., Raskin, M., and Hendrikx, A. (1960). Fluorimetric determination of free plasma 11-hydroxycorticosteroids in man. Acta endocr., 33, 297-307.

Elmadjian, F., Hope, J. M., and Lanson, E. T. (1956). Excretion of epinephrine and norepinephrine in various emotional states. J. clin. Endocr., 17, 608-619.

Euler, U. S. von (1964). Commentary on quantitation of stress by catecholamine analysis. Clin. Pharmacol Ther., 5, 398-404.

- and Lundberg, U. (1954). Effect of flying on the epinephrine excretion in air force personnel. $J$. appl. Physiol., 6, 551-555.

Funkenstein, D. H., Greenblatt, M., and Solomon, H. C. (1952). Nor-epinephrine-like and epinephrine-like substances in psychotic and psychoneurotic patients. Amer. J. Psychiat., 108, 652-662.

Goodall, M., and Berman, M. L. (1960). Urinary output of adrenaline, noradrenaline, and 3-methoxy-4-hydroxymandelic acid following centrifugation and anticipation of centrifugation. J. clin. Invest., 39, 1533-1538.

Gross, E., Bock, M., and Hellrung, F. (1942). Zur Toxikologie des Nitroglykols in vergleich zu der des Nitroglycerines. Arch. exp. Path. Pharmakol., 200, 271-304.

Häggendal, J., Johnsson, G., and Lund, R. P. (1968). The plasma content and excretion of catecholamines in nitroglycerine workers. Brit. J. industr. Med., 25, 241-242.

Hasegawa, H., and Sato, M. (1963a). Experimental study on the nitroglycol poisoning. Industr. Hlth (Kawasaki), 1, 20-27.

Hotta, K., and Yamada, R. (1963). On the influence of noradrenaline upon the blood pressure of workers exposed to nitroglycol and the change of the concentration of noradrenaline and adrenaline in the urine. Int. Arch. Gewerbepath., 20, 311-315.

Kubota, J., Ishizu, S., Yamamura, T., Hideo, S., and Kato, M. (1962). A study on the poisonous effects of dynamite substances (1) (in Japanese). Jap. J. industr. Hlth, 4, 613-617.

Raab, W., Chaplin, J. P., and Bajusz, E. (1964). Myocardial necroses produced in domesticated rats and in wild rats by sensory and emotional stresses. Proc. Soc. exp. Biol. (N.Y.), 116, 665-669.

- Stark, E., and Gigee, W. R. (1959). Role of catecholamines in the origin of stress-induced myocardial necrosis. Circulation, 20, 754.

_, - Macmillan, W. H., and Gigee, W. R. (1961). Sympathogenic origin and antiadrenergic prevention of stress-induced myocardial lesions. Amer. J. Cardiol., 8, 203-221.

Reichenbach, D., Greenhoot, J. H., and Benditt, E. P. (1969). Cardiac necrosis produced by endogenous catecholamines. Fed. Proc., 28, 748.

Saito, H. (1971). Personal communication.

Sakabe, H. (1961). On the nitroglycol poisoning (in Japanese). Jap. J. industr. Hlth, 3, 317-323.

Schümann, H. J. (1970). Effect of angiotensin on noradrenaline release of the isolated rabbit heart. In New Aspects of Storage and Release Mechanism of Catecholamines, pp. 202-211. Springer-Verlag, Berlin. 
Symanski, H. (1952). Schwere Gesundheitsschädingungen durch berufliche Nitroglykoleinwirkung. Arch. Hyg., 136, 139-158.

Vigliani, E. C., Cavagna, G., Locati, G., and Foa, V. (1968). Biological effects of nitroglycol on the metabolism of catecholamines. Arch. environm. Hlth, 16, 477-484.

Weil-Malherbe, H., Smith, E. R. B., and Bowles, G. R. (1968). Excretion of catecholamines and catecholamine metabolites in project mercury pilots. J. appl. Physiol., 24, 146-151.
Wilhelmi, H. (1942). Studien über Methämoglobinbildung. Arch. exp. Path. Pharmakol., 200, 305-323.

Yoshikawa, H. (1964). Effects of adrenaline on nitroglycol poisoned mice. Industr. Hlth (Kawasaki), 2, 127-128.

- (1965). Changes of sensitivity to adrenaline on the nitroglycol poisoned mice. Industr. Hlth (Kawasaki), 3, 86-90.

Received for publication June 8, 1971.

\section{The April (1972) Issue}

The meaning of modern audiological tests in relation to noise-induced deafness: a review T. J. WILMOT

A study of the mortality of female asbestos workers MURIEL L. Newhouse, G. BerRy, J. C. WAGNer, AND MARY E. TUROK

A mortality study of shipyard workers with pleural plaques D. E. FLETCHER

Electron microscope characteristics of inhaled asbestos fibre F. D. POOLEY

A histochemical study of the asbestos body coating M. Governa AND C. ROSANDA

Lung dust and lung iron contents of coal workers in different coalfields in Great Britain I. BERGMAN

AND C. CASSWELl

Chronic exposure to iron oxide, chromium oxide, and nickel oxide fumes of metal dressers in a steelworks J. Graham Jones and C. G. Warner

Graphite pneumoconiosis K. W. Ranasinha AND C. G. URAgoda

Study of lung function changes among different grades of byssinosis Y. M. EL-SADIK, M. MoseLHI, A. R. El-Hinady, AND M. N. Mostafa

Scrotal cancer in the north-west of England 1962-68 W. R. LeE, M. R. Alderson, AND JeAN E. Downes A study of the medical causes of absence from duty aboard South African merchant ships SAMUEL LeVY Mortality of shift and day workers 1956-68 P. J. TAYLOR AND S. J. Pocock

Absenteeism of shift and day workers P. J. TAYLOR, S. J. POCOCK, AND R. SERGEAN

Some effects of ultrasound on guinea-pig ear skin Shirley A. Carney, J. C. LaWrence, AND C. R. RICKETTS

Notes and miscellanea

Occupational health in Great Britain in 1970 R. S. F. ScHILLING

Chronic inorganic mercury poisoning treated with N-acetyl-D-penicillamine $R$. F. GLEDHILL AND

A. P. Hopkins

Book reviews

Information section

A number of copies are still available and may be obtained from the Publishing Manager, British Medical Association, Tavistock Square, London WC1H 9JR price $£ 1.25$ ( $£ 1.50$ in countries overseas; U.S.A. \$3.60). 